\title{
Florística e fitossociologia do componente arbóreo da transição Floresta Ombrófila Densa das Terras Baixas - Floresta Ombrófila Densa Submontana do Núcleo Picinguaba/PESM, Ubatuba, sudeste do Brasil
}

\author{
Mariana Cruz Rodrigues de Campos ${ }^{1,3}$, Jorge Yoshio Tamashiro ${ }^{1}$, \\ Marco Antonio Assis ${ }^{2} \&$ Carlos Alfredo Joly ${ }^{1}$ \\ ${ }^{1}$ Departamento de Biologia Vegetal, Instituto de Biologia, \\ Universidade Estadual de Campinas - UNICAMP, CP 6109, CEP 13083-970, Campinas, SP, Brasil, \\ e-mail:maricruzcampos@gmail.com; tamashi@unicamp.br; cjoly@unicamp.br \\ ${ }^{2}$ Departamento de Botânica, Instituto de Biociências de Rio Claro, \\ Universidade Estadual Paulista “Júlio de Mesquita Filho” - UNESP, CP 199, CEP 13506-900, \\ Rio Claro, SP, Brasil,e-mail: massis@rc.unesp.br \\ ${ }^{3}$ Autor para correspondência: Mariana Cruz,Rodrigues de Campos, e-mail: maricruzcampos@gmail.com
}

CAMPOS, M.C.R., TAMASHIRO, J.Y., ASSIS, M.A. \& JOLY, C.A. Phytosociology and floristic composition of the arboreal component of the transition Lowland - Lower Montane Ombrophilous Dense Forest at Núcleo Picinguaba/Serra do Mar State Park, Ubatuba, southeastern Brazil. Biota Neotrop. 11(2): http:// www.biotaneotropica.org.br/v11n2/en/abstract?inventory+bn02311022011.

\begin{abstract}
In a 1-ha plot divided into 100 subplots of $10 \times 10 \mathrm{~m}$, all trees with at least $15 \mathrm{~cm}$ of perimeter at breast height $(\mathrm{DBH}=4.8 \mathrm{~cm})$ were marked and had their heights estimated and perimeter taken. The rock cover (rocks over $50 \mathrm{~cm}$ diameter) was estimated in five classes of frequency, and records were made for individuals growing directly on rocks. We found 1,274 trees matching the sampling criteria, which belong to 41 botanical families (highlighting Myrtaceae, Rubiaceae and Fabaceae) and 142 species or morphotypes. The most important (Importance Value Index) species are: Euterpe edulis, Mollinedia schottiana, Bathysa mendoncaei, Coussarea accedens, Rustia formosa and Guapira opposita. Shannon's diversity index was 4.05 nats/ind and Pielou's equability was 0.82 . The average tree height is of $9 \mathrm{~m}$ and the canopy is at around $18 \mathrm{~m}$. The trees' average diameter is $13.9 \mathrm{~cm}$, and 29 individuals surpass $50 \mathrm{~cm} \mathrm{DBH}$. The basal area for the 1-ha plot (live trees only) is $30.27 \mathrm{~m}^{2}$. A direct relation was found between rock cover and lesser species richness and number of individuals per subplot. No relationship was found between rock cover and the mean height or mean diameter of stems in the subplots. 34 tree species in this area are able to grow on rocks; 11 of which do not grow roots to the soil, particularly Euterpe edulis and Guapira opposita. The height and diameter of the individuals that grow on rocks is not statistically different from the remaining in the plot.
\end{abstract}

Keywords: Atlantic rainforest, floristic, phytosociology, Serra do Mar State Park.

CAMPOS, M.C.R., TAMASHIRO, J.Y., ASSIS, M.A. \& JOLY, C.A. Florística e fitossociologia do componente arbóreo da transição Floresta Ombrófila Densa das Terras Baixas - Floresta Ombrófila Densa Submontana do Núcleo Picinguaba/PESM, Ubatuba, sudeste do Brasil. Biota Neotrop. vol. 11(2): http://www.biotaneotropica. org.br/v11n2/pt/abstract?inventory+bn02311022011.

Resumo: Em uma parcela de 1 ha dividida em 100 subparcelas de $10 \times 10 \mathrm{~m}$ foram plaqueados todos os indivíduos arbóreos com no mínimo $15 \mathrm{~cm}$ de perímetro à altura do peito $(\mathrm{DAP}=4,8 \mathrm{~cm})$, e suas alturas foram estimadas e o perímetro medido. Todas as subparcelas tiveram a cobertura por rochas maiores que $50 \mathrm{~cm}$ de diâmetro estimada em cinco classes de frequência, e foram anotados os indivíduos que crescem diretamente sobre as rochas. Foram encontradas 1.274 árvores dentro do critério amostral, pertencentes a 41 famílias botânicas (com destaque para Myrtaceae, Rubiaceae e Fabaceae) e 142 espécies ou morfotipos. As espécies mais importantes (Índice de Valor de Importância) são: Euterpe edulis, Mollinedia schottiana, Bathysa mendoncaei, Coussarea accedens, Rustia formosa e Guapira opposita. O índice de diversidade de Shannon foi de 4,05 nats/ind e de equiabilidade de Pielou, de 0,82 . A altura média das árvores é de $9 \mathrm{~m}$, e o dossel está a cerca de $18 \mathrm{~m}$. O diâmetro médio dos indivíduos é de 13,9 cm, e 29 indivíduos ultrapassam os $50 \mathrm{~cm}$ DAP. A área basal somada do hectare é de 30,27 $\mathrm{m}^{2}$ (árvores vivas). Foi encontrada uma relação direta entre a cobertura por rochas e menor riqueza de espécies e número de indivíduos por subparcela. Nenhuma relação foi encontrada entre os afloramentos rochosos e a altura média e diâmetro médio nas subparcelas. 34 espécies arbóreas nesta área amostral são capazes de crescer sobre rochas; 11 delas sem lançar raízes para o solo, com destaque para Euterpe edulis e Guapira opposita. A altura e diâmetro dos indivíduos que crescem sobre rochas não difere estatisticamente do restante dos indivíduos da parcela. Palavras-chave: Mata Atlântica, florística, fitossociologia, Parque Estadual da Serra do Mar. 


\section{Introdução}

Estudos de florística e fitossociologia tratam de conhecer quais espécies estão presentes em dada área e a estrutura desta vegetação; ou seja, a quantidade de indivíduos por espécie, as respectivas classes de tamanho e seu arranjo espacial (Rejmanék 1977).

Oliveira-Filho \& Fontes (2000) estudaram a variação florística em escala regional na Floresta Ombrófila Densa Atlântica, e encontraram relações com o clima, concordando com a observação de Clark et al. (1998) para a Amazônia, de que em escala de paisagem, os fatores como temperatura e precipitação respondem pelas variações na composição e abundância de espécies.

O objetivo deste trabalho é determinar a composição florística e a estrutura do componente arbóreo da faixa de transição entre a Floresta Ombrófila Densa das Terras Baixas e a Floresta Ombrófila Densa Submontana, no Núcleo Picinguaba, Parque Estadual da Serra do Mar em Ubatuba/SP, Brasil.

\section{Material e Métodos}

\section{1. Área de estudo}

A área de estudo está localizada no núcleo Picinguaba do Parque Estadual da Serra do Mar, situando-se sobre a Trilha do Corisco, a aproximadamente $20 \mathrm{~m}$ da margem direita do Rio da Fazenda, no bairro Fazenda da Caixa, município de Ubatuba, nas coordenadas $23^{\circ} 20^{\prime} 2,88^{\prime \prime} \mathrm{S}$ e $44^{\circ} 49^{\prime} 56,22^{\prime \prime} \mathrm{O}$.

Toda a encosta entre a Casa de Farinha e a parcela estudada neste trabalho apresenta muitas rochas na superfície, provavelmente originárias de rolamento, e que chegam a ter $5 \mathrm{~m}$ de diâmetro. A maior parte delas, no entanto, mede cerca de 50 a $100 \mathrm{~cm}$ de diâmetro.

O clima é definido por um verão chuvoso, geralmente com poucos episódios de muita pluviosidade; e inverno com temperaturas maiores que $18{ }^{\circ} \mathrm{C}$. Desde 1997, durante os meses de junho, julho e agosto, foi registrado um déficit hídrico (São Paulo 2006).

As análises físicas e químicas de solo foram realizadas pelo laboratório do CENA (Centro de Energia Nuclear na Agricultura USP). Uma trincheira foi aberta fora da parcela para observação do perfil do solo; em 8 subparcelas foram feitas análises de porcentagem de argila, areia e silte; e em 16 subparcelas equiidistantes foram quantificados os parâmetros $\mathrm{pH}\left(\mathrm{em} \mathrm{CaCl}_{2}\right), \mathrm{H}+\mathrm{Al}, \mathrm{K}, \mathrm{Al}, \mathrm{S}, \mathrm{P}, \mathrm{Ca}$, $\mathrm{Mg}$, Soma de Bases (SB) e Capacidade de Troca Catiônica (CTC). As análises foram feitas separadamente para diferentes profundidades, mas neste trabalho, o valor utilizado é a média dos resultados dos $30 \mathrm{~cm}$ superficiais do solo para cada um dos parâmetros, pois esta é a camada onde ocorrem predominantemente as raízes (Martins 2010)

O método de amostragem e o protocolo utilizado para a seleção da área e demarcação da parcela estão descritos detalhadamente em Joly et al. (2011).

A coleta do material botânico foi realizada com o auxílio de uma tesoura de poda e extensões que possibilitavam a coleta até $18 \mathrm{~m}$ de altura. Os indivíduos que não possuíam nenhum ramo até esta altura foram escalados através da técnica de cordas, visando minimizar o impacto nas árvores. O material foi todo herborizado segundo as técnicas de Fidalgo \& Bononi (1984).

O material coletado foi identificado previamente para depois ser comparado com os materiais das coleções dos herbários da Universidade Estadual de Campinas (UEC) e também da Universidade de São Paulo (SP) e Universidade Estadual Paulista (HRCB). Especialistas forneceram ajuda imprescindível no caso de famílias de identificação mais difícil, como Myrtaceae, Rubiaceae e Lauraceae.
A classificação segue a nomenclatura proposta pelo Angiosperm Phylogeny Group (APG II 2003), que considera também características moleculares para a classificação.

\section{Análise dos dados}

Os parâmetros fitossociológicos, como número de indivíduos, área basal por subparcela, diversidade de Shannon (H'), eqüabilidade de Pielou (J) e índices de valor de importância (IVI) das espécies foram calculados através do software FITOPAC 1.6.4 (Shepherd 2006). Os indivíduos mortos foram considerados nas contagens de indivíduos por subparcela e na área basal.

\section{Resultados}

\section{Variáveis ambientais}

A parcela possui variação altitudinal de 64 a 89 m acima do nível do mar, e inclinação variando de 2 a $35,4^{\circ}$. As estimativas de cobertura do solo por rochas, os pontos onde ha afloramento de um riacho e o percurso da trilha, onde ocorre pisoteamento, são apresentados na Figura 1.

Os valores da análise de solo em 16 pontos (Tabela 1) mostraram que o solo da parcela é muito ácido, com pH variando de 3,38 a 3,93. Os valores encontrados de concentração de fósforo e enxofre foram os mais variáveis dentre as subparcelas, com valores que vão de 5,51 a 49,00 mg. $\mathrm{kg}^{-1}(\mathrm{P})$ e 6,25 a 58,00 mg.kg-1 (S). Houve o caso, tanto com cálcio como com alumínio, de haver apenas uma amostra com valor altamente distinto. A subparcela 91 possui 17,25 mmolc. $\mathrm{kg}^{-1} \mathrm{Ca}$, enquanto a média sem este valor é de 2,41. Para o caso do alumínio, a parcela 94 teve valor de 4,00 contra a média de 14,57 mmolc. $\mathrm{kg}^{-1}$ sem este valor.

A porcentagem de areia, argila e silte foi avaliada somente para oito pontos, dos quais apenas um teve resultado visivelmente

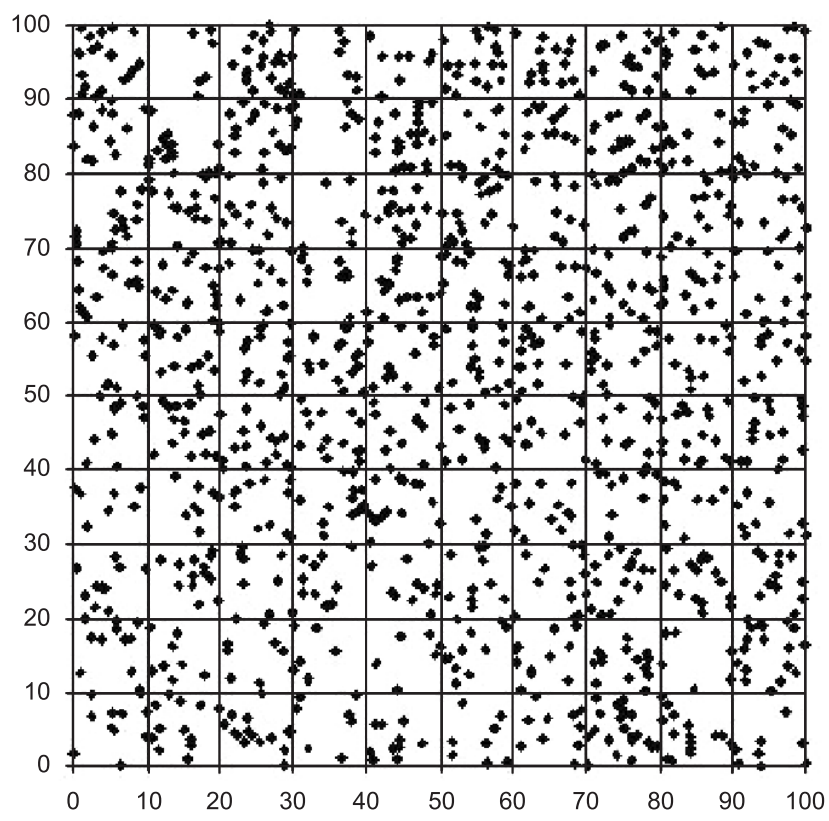

Figura 1. Porcentagem de rochas maiores que $50 \mathrm{~cm}$ de diametro afloradas do solo (em escala de cores); pontos com agua na superficie (x preto); e percurso da trilha (linha preta).

Figure 1. Percentage of outcrop rocks larger than $50 \mathrm{~cm}$ in diameter (in colour scale); sites where surface water streams occur (black x); and position of the track (black line). 
Tabela 1. Amplitude de resultados, valores médios e desvio padrão para as variáveis de solo. Foram considerados os valores obtidos para os 30 cm superficiais de solo em 16 pontos no hectare.

Table 1. Range of results, mean and standard deviation of the soil results values. These results correspond to the top $30 \mathrm{~cm}$ of soil in 16 samples in the hectare.

\begin{tabular}{|c|c|c|c|}
\hline & Faixa & Média & Desvio Padrão \\
\hline Areia/Sand (\%) & $56,32-90,43$ & 66,42 & 3,66 \\
\hline Argila/Clay (\%) & $6,04-35,97$ & 26,73 & 3,36 \\
\hline Silte/Silt (\%) & $3,53-10,84$ & 6,85 & 0,73 \\
\hline $\mathrm{pH}(\mathrm{CaCl} 2)$ & $3,36-3,93$ & 3,66 & 0,21 \\
\hline P (mg.kg-1) & $5,51-49$ & 11,77 & 10,15 \\
\hline $\mathrm{K}\left(\mathrm{mmolc} \cdot \mathrm{kg}^{-1}\right)$ & $0,7-1,97$ & 1,19 & 0,35 \\
\hline $\mathrm{Ca}\left(\right.$ mmolc. $\left.\mathrm{kg}^{-1}\right)$ & $1-17,25$ & 3,33 & 3,83 \\
\hline $\mathrm{Mg}\left(\mathrm{mmolc} \cdot \mathrm{kg}^{-1}\right)$ & $0-4,25$ & 1,91 & 1,16 \\
\hline $\mathrm{Al}\left(\mathrm{mmolc} \cdot \mathrm{kg}^{-1}\right)$ & $4-24,2$ & 13,91 & 4,30 \\
\hline $\mathrm{S}\left(\mathrm{mg} \cdot \mathrm{kg}^{-1}\right)$ & $6,25-58$ & 33,80 & 17,82 \\
\hline $\mathrm{H}+\mathrm{Al}\left(\mathrm{mmolc} \cdot \mathrm{kg}^{-1}\right)$ & $55,25-173$ & 102,11 & 41,46 \\
\hline $\mathrm{SB}($ mmolc.kg-1 $)$ & $2,53-23,13$ & 6,43 & 4,69 \\
\hline CTC $\left(\right.$ mmolc. $\left.\mathrm{kg}^{-1}\right)$ & $58,39-179,05$ & 108,54 & 41,30 \\
\hline
\end{tabular}

diferente: novamente na parcela 94, onde o solo é composto por $90,43 \%$ areia; $6,04 \%$ argila e $3,53 \%$ silte. É importante ressaltar que nesta subparcela há uma mina d'água.

O solo da área, do tipo Cambissolo Háplico (Instituto..., 2007), não possui erosão aparente, é bem drenado e é originário de sedimentos arenosos do Holoceno. Em termos de características morfológicas, ele é um solo de textura argilosa, friável, ligeiramente plástico e ligeiramente pegajoso (Martins 2010).

O solo possui quatro horizontes: $\mathrm{A}(0-15 \mathrm{~cm}), \mathrm{AB}(15-32 \mathrm{~cm}), \mathrm{B} 1$ $(32-90 \mathrm{~cm})$ e B2 $(90-140 \mathrm{~cm})$. As raízes finas e grossas são numerosas no primeiro e segundo, enquanto no horizonte B1 encontram-se apenas raízes finas esparsas. Sua cor é bruno-amarelada (10YR 5/8), sendo mais escuro apenas no horizonte A (10YR 3/4) (Martins 2010)

\section{Florística}

Na parcela de 1 ha, foram amostrados 1.274 indivíduos dentro dos critérios amostrais (Figura 2), dos quais 34 (2,7\%) estavam mortos ou sem copa. O número de famílias encontradas foi 41 , e o de espécies e morfotipos foi de 142 (Tabela 2).

Foram identificadas em campo todas as 187 palmeiras (Família Arecaceae), pois estas são pertencentes a apenas três espécies. Euterpe edulis Mart., conhecida popularmente como palmito-jussara, foi a espécie mais abundante, com 143 indivíduos. Na família, seguem Syagrus pseudococos (Raddi) Glassman, o pati, com 37 indivíduos e Astrocaryum aculeatissimum (Schott) Burret, a brejaúva, com sete indivíduos (embora devido ao crescimento clonal, haja 16 troncos).

Os quatro fetos arborescentes (Família Cyatheaceae), conhecidos popularmente como samambaia-uçu encontrados pertencem a duas espécies: Alsophila sternbergii e Cyathea phalerata; e nenhum deles apresenta fustes múltiplos.

Das demais famílias, destacam-se por sua riqueza Myrtaceae (27 espécies ou morfoespécies), Rubiaceae (14) e Fabaceae (11). Seguem-se a estas Euphorbiaceae e Lauraceae, com oito espécies cada e Moraceae e Sapotaceae, com sete. No outro extremo, há 19 famílias representadas por somente uma espécie e 10 com apenas duas espécies (Tabela 2).

Em termos de abundância, Myrtaceae e Rubiaceae também encabeçam a lista, com a diferença que três espécies de Rubiaceae

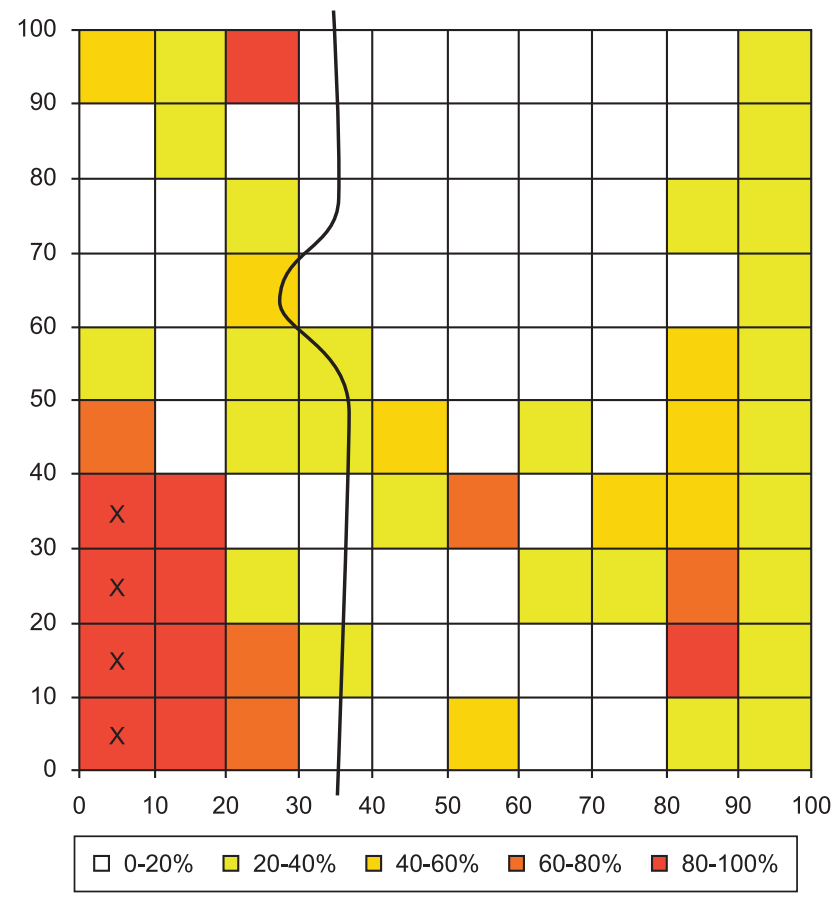

Figura 2. Localização dos indivíduos dentro das subparcelas de $10 \times 10 \mathrm{~m}$.

Figure 2. Position of the individuals inside the $10 \times 10 \mathrm{~m}$ subplots.

são responsáveis por $14 \%$ dos indivíduos no hectare (e a família como um todo; 19\%), enquanto o número de indivíduos de cada espécie de Myrtaceae é mais igualmente distribuído dentro da família para somar seus $17 \%$.

No hectare amostrado, nenhuma espécie encontrada é nova para a ciência, mas Gomidesia cf. blanchetiana O. Berg e Mollinedia lamprophylla Perkins não estão listadas em outros estudos no Estado de São Paulo. Mollinedia lamprophylla, que foi amostrada com sete indivíduos (dois deles com frutos), se encontra na lista vermelha da IUCN como espécie ameaçada de extinção. 
Tabela 2. Lista das espécies e morfotipos arbóreos encontrados. Ao lado do nome da família está seu número de indivíduos em parênteses e na terceira coluna (N), a abundância de cada espécie.

Table 2. Tree species and morphotypes list. Next to the botanical family name is the number of individuals in brackets, and in the third column (N) is the abundance of each species.

\begin{tabular}{|c|c|c|}
\hline Família & Espécie & $\mathbf{N}$ \\
\hline \multirow[t]{2}{*}{ Annonaceae (9) } & Guatteria australis A. St.-Hil. & 8 \\
\hline & Rollinia sericea (R.E. Fr.) R.E. Fr. & 1 \\
\hline \multirow[t]{2}{*}{ Apocynaceae (7) } & Malouetia arborea (Vell.) Miers & 3 \\
\hline & Tabernaemontana laeta Mart. & 4 \\
\hline \multirow[t]{4}{*}{ Araliaceae (18) } & Dendropanax cuneatus (DC.) Decne. \& Planch. & 7 \\
\hline & Oreopanax capitatus (Jacq.) Decne. \& Planch. & 1 \\
\hline & Schefflera angustissima (Marchal) Frodin & 1 \\
\hline & Schefflera calva (Cham.) Frodin \& Fiaschi & 9 \\
\hline \multirow[t]{3}{*}{ Arecaceae (187) } & Astrocaryum aculeatissimum (Schott) Burret & 7 \\
\hline & Euterpe edulis Mart. & 143 \\
\hline & Syagrus pseudococos (Raddi) Glassman & 37 \\
\hline Asteraceae (2) & Vernonia discolor (Spreng.) Less. & 2 \\
\hline \multirow[t]{2}{*}{ Boraginaceae (4) } & Cordia cf. sellowiana Cham. & 1 \\
\hline & Cordia taguahyensis Vell. & 3 \\
\hline Cardiopteridaceae (6) & Citronella paniculata (Mart.) R.A. Howard & 6 \\
\hline Caricaceae (4) & Jacaratia heptaphylla (Vell.) A. DC. & 4 \\
\hline \multirow[t]{4}{*}{ Celastraceae (15) } & Maytenus ardisiifolia Reissek & 3 \\
\hline & Maytenus robusta Reissek & 2 \\
\hline & Maytenus sp3 & 3 \\
\hline & Salacia grandifolia (Mart.) G. Don & 7 \\
\hline \multirow[t]{2}{*}{ Chrysobalanaceae (19) } & Couepia venosa Prance & 9 \\
\hline & Hirtella hebeclada Moric. ex DC. & 10 \\
\hline Clusiaceae (30) & Garcinia gardneriana (Planch. \& Triana) Zappi & 30 \\
\hline \multirow[t]{2}{*}{ Combretaceae (4) } & Buchenavia kleinii Exell & 1 \\
\hline & Terminalia januarensis DC. & 3 \\
\hline \multirow[t]{2}{*}{ Cyatheaceae (4) } & Alsophila sternbergii (Sternb.) D.S. Conant & 2 \\
\hline & Cyathea phalerata Mart. & 2 \\
\hline Dichapetalaceae (4) & Stephanopodium estrellense Baill. & 4 \\
\hline \multirow[t]{2}{*}{ Elaeocarpaceae (18) } & Sloanea guianensis (Aubl.) Benth. & 17 \\
\hline & Sloanea monosperma Vell. & 1 \\
\hline Erythroxylaceae (1) & Erythroxylum sp. 1 & 1 \\
\hline \multirow[t]{7}{*}{ Euphorbiaceae (34) } & Alchornea glandulosa Poepp. & 2 \\
\hline & Alchornea triplinervia (Spreng.) Müll. Arg. & 12 \\
\hline & Euphorbiaceae sp. 1 & 1 \\
\hline & Mabea piriri Aubl. & 1 \\
\hline & Pausandra morisiana (Casar.) Radlk. & 16 \\
\hline & Sapium glandulosum (L.) Morong & 1 \\
\hline & Tetrorchidium rubrivenium Poepp. & 1 \\
\hline \multirow[t]{11}{*}{ Fabaceae (41) } & Copaifera langsdorffii Desf. & 1 \\
\hline & Copaifera trapezifolia Hayne & 2 \\
\hline & Dahlstedtia pinnata (Benth.) Malme & 2 \\
\hline & Hymenea courbaril L. & 1 \\
\hline & Inga edulis Mart. & 4 \\
\hline & Inga striata Benth. & 2 \\
\hline & Myrocarpus frondosus Allemão & 1 \\
\hline & Platymiscium floribundum Vogel & 1 \\
\hline & Sclerolobium denudatum Vogel & 10 \\
\hline & Swartzia simplex var. grandiflora (Raddi) R.S. Cowan & 15 \\
\hline & Zollernia ilicifolia (Brongn.) Vogel & 2 \\
\hline
\end{tabular}


Florística e Fitossociologia de Floresta Submontana

Tabela 2. Continuação...

\begin{tabular}{|c|c|c|}
\hline Família & Espécie & $\mathbf{N}$ \\
\hline Lamiaceae (2) & Aegiphila sellowiana Cham. & 2 \\
\hline \multirow[t]{9}{*}{ Lauraceae (27) } & Cryptocarya mandiocana & 1 \\
\hline & Cryptocarya mandiocana Meisn. & 1 \\
\hline & Cryptocarya saligna $\mathrm{Mez}$ & 7 \\
\hline & Endlicheria paniculata (Spreng.) J.F. Macbr. & 1 \\
\hline & Licaria armeniaca (Nees) Kosterm. & 6 \\
\hline & Ocotea dispersa (Nees) Mez & 5 \\
\hline & Ocotea glaziovii $\mathrm{Mez}$ & 1 \\
\hline & Ocotea velloziana (Meisn.) Mez & 4 \\
\hline & Rhodostemonodaphne macrocalyx (Meisn.) Rohwer ex Madriñán & 1 \\
\hline Lecythidaceae (4) & Cariniana estrellensis (Raddi) Kuntze & 4 \\
\hline Magnoliaceae (1) & Magnolia ovata (A. St.-Hil) Spreng. & 1 \\
\hline \multirow[t]{2}{*}{ Malvaceae (14) } & Eriotheca pentaphylla (Vell.) A. Robyns & 7 \\
\hline & Quararibea turbinata (Sw.) Poir. & 7 \\
\hline Melastomataceae (1) & Miconia cf. prasina Sw. (DC.) & 1 \\
\hline \multirow[t]{4}{*}{ Meliaceae (11) } & Cabralea canjerana (Vell.) Mart. & 2 \\
\hline & Cedrella fissilis Vell. & 1 \\
\hline & Guarea macrophylla subsp. tuberculata (Vell.) T.D. Penn. & 2 \\
\hline & Trichilia silvatica C. DC. & 6 \\
\hline \multirow[t]{4}{*}{ Monimiaceae (95) } & Mollinedia boracensis Peixoto & 3 \\
\hline & Mollinedia lamprophylla Perkins & 7 \\
\hline & Mollinedia schottiana (Spreng.) Perkins & 81 \\
\hline & Mollinedia triflora (Spreng.) Tul. & 4 \\
\hline \multirow[t]{7}{*}{ Moraceae (36) } & Brosimum guianense Aubl. Huber & 9 \\
\hline & Brosimum lactescens (S. Moore) C.C. Berg & 2 \\
\hline & Ficus glabra Vell. & 3 \\
\hline & Ficus insipida Willd. & 1 \\
\hline & Ficus pulchella Schott ex Spreng. & 1 \\
\hline & Sorocea bonplandii (Baill.) W.C. Burger, Lanj. \& Wess. Boer & 14 \\
\hline & Sorocea hilarii Gaudich. & 6 \\
\hline Myristicaceae (16) & Virola bicuhyba (Schott ex Spreng.) Warb. & 16 \\
\hline \multirow[t]{2}{*}{ Myrsinaceae (6) } & Ardisia martiana Miq. & 5 \\
\hline & Rapanea gardneriana (A. DC.) Mez & 1 \\
\hline \multirow[t]{18}{*}{ Myrtaceae (223) } & Calyptranthes lucida Mart. ex DC. & 10 \\
\hline & Calyptranthes rufa O. Berg & 2 \\
\hline & Calyptranthes strigipes O. Berg & 6 \\
\hline & Campomanesia guaviroba (DC.) Kiaersk. & 3 \\
\hline & Campomanesia phaea (O. Berg) Landrum & 5 \\
\hline & Eugenia cf. cerasiflora Miq. & 1 \\
\hline & Eugenia cf. cereja D. Legrand & 22 \\
\hline & Eugenia cf. fusca O. Berg & 2 \\
\hline & Eugenia excelsa $\mathrm{O}$. Berg & 1 \\
\hline & Eugenia fusca O. Berg & 1 \\
\hline & Eugenia linguaeformis O. Berg & 9 \\
\hline & Eugenia magnibracteolata Mattos \& D. Legrand & 1 \\
\hline & Eugenia neoaustralis Sobral & 4 \\
\hline & Eugenia oblongata $\mathrm{O}$. Berg & 26 \\
\hline & Eugenia plicata Nied. & 2 \\
\hline & Eugenia prasina $\mathrm{O}$. Berg & 22 \\
\hline & Eugenia sp. 1 & 12 \\
\hline & Eugenia subavenia $\mathrm{O}$. Berg & 3 \\
\hline
\end{tabular}


Tabela 2. Continuação...

\begin{tabular}{|c|c|c|}
\hline Família & Espécie & $\mathbf{N}$ \\
\hline \multirow[t]{9}{*}{ Myrtaceae (223) } & Gomidesia cf. blanchetiana O. Berg & 9 \\
\hline & Marlierea glazioviana Kiareskou & 5 \\
\hline & Marlierea obscura O. Berg & 19 \\
\hline & Marlierea silvatica (Gardner) Kiaersk. & 1 \\
\hline & Marlierea tomentosa Cambess. & 15 \\
\hline & Myrcia richardiana (O. Berg) Kiaersk. & 1 \\
\hline & Myrcia spectabilis DC. & 30 \\
\hline & Myrciaria floribunda (H. West ex Willd.) O. Berg & 10 \\
\hline & Plinia complanata M.L. Kawas. \& B. Holst & 1 \\
\hline Nyctaginaceae (40) & Guapira opposita (Vell.) Reitz & 40 \\
\hline Ochnaceae (2) & Ouratea parviflora Baill. & 2 \\
\hline \multirow[t]{2}{*}{ Olacaceae (15) } & Heisteria silvianii Schwacke & 1 \\
\hline & Tetrastylidium engleri Schwacke & 14 \\
\hline Phyllantaceae (6) & Hieronyma alchorneoides Allemão & 6 \\
\hline Proteaceae (2) & Roupala paulensis Sleumer & 2 \\
\hline \multirow[t]{15}{*}{ Rubiaceae (245) } & Alseis floribunda Schott & 8 \\
\hline & Bathysa australis (A. St.-Hil.) Benth. \& Hook. f. & 3 \\
\hline & Bathysa mendoncaei K. Schum. & 67 \\
\hline & Coussarea accedens Müll. Arg. & 67 \\
\hline & Coussarea meridionalis (Vell.) Müll. Arg. & 35 \\
\hline & Faramea pachyanta Müll. Arg. & 1 \\
\hline & Faramea picinguabae M. Gomes & 6 \\
\hline & Ixora heterodoxa Müll. Arg. & 1 \\
\hline & Posoqueria cf. latifolia (Rugde) Roem. \& Schult. & 1 \\
\hline & Rubiaceae sp. & 1 \\
\hline & Rudgea coronata subsp. leiocarpoides (Müll. Arg.) Zappi & 2 \\
\hline & Rudgea vellerea Müll. Arg. & 4 \\
\hline & Rustia formosa (Cham. \& Schltdl. ex DC.) Klotzsch & 44 \\
\hline & Simira sampaioana (Standl.) Steyerm. & 4 \\
\hline & Simira viridiflora (Allemão \& Saldanha) Steyerm. & 1 \\
\hline Rutaceae (1) & Zanthoxylum fagara (L.) Sarg. & 1 \\
\hline Sapindaceae (2) & Cupania oblongifolia Mart. & 2 \\
\hline \multirow[t]{7}{*}{ Sapotaceae (65) } & Chrysophyllum flexuosum Mart. & 43 \\
\hline & Chrysophyllum viride Mart. \& Eichler & 2 \\
\hline & Ecclinusa ramiflora Mart. & 9 \\
\hline & Pouteria psammophila (Mart.) Radlk. & 2 \\
\hline & Pouteria venosa (Mart.) Baehni & 7 \\
\hline & Sapotaceae sp. 1 & 1 \\
\hline & Sapotaceae sp. 2 & 1 \\
\hline Solanaceae (1) & Solanaceae sp. 1 & 1 \\
\hline \multirow[t]{3}{*}{ Urticaceae (18) } & Cecropia glaziovi Snethl. & 9 \\
\hline & Coussapoa microcarpa (Schott) Rizzini & 4 \\
\hline & Pourouma guianensis Aubl. & 5 \\
\hline Mortas (34) & Mortas & 34 \\
\hline Total geral & & 1274 \\
\hline
\end{tabular}

Os números de campo dos indivíduos pertencentes a cada espécie encontram-se no Anexo 1 (disponível na versão online, como Supplementary Online Material/SOM).

\section{Fitossociologia}

Os valores encontrados para os índices descritores da comunidade de diversidade de Shannon e eqüabilidade de Pielou foram, respectivamente, $H^{\prime}=4,051$ nats/ind e $\mathrm{J}=0,817$. A área basal de árvores vivas do hectare foi de $30,27 \mathrm{~m}^{2}$.

A relação de dominância das espécies fica evidente na Figura 3, onde se vê que a comunidade é marcada por quatro espécies em maior número (Euterpe edulis, Mollinedia schottiana, Bathysa mendoncaei e Coussarea accedens), mas seguida de uma longa cauda de espécies com menos indivíduos. Segundo a terminologia adotada por Moreira 
(2007), somente Euterpe edulis pode ser considerada abundante, pois possui mais de 100 indivíduos por hectare. As 28 espécies com 10 a 99 indivíduos por hectare seriam consideradas constantes, enquanto as 113 demais seriam comuns ou ocasionais.

Foram encontradas muitas espécies representadas por poucos indivíduos na parcela amostral. São 43 espécies com apenas por um indivíduo; 22 com dois e 10 com três indivíduos. Estas três classes somam mais da metade $(52,8 \%)$ das espécies encontradas, sendo que em número de indivíduos, seriam apenas 9,2\%. As espécies com até nove indivíduos somam menos de um terço dos indivíduos amostrados $(28,5 \%)$, mas ultrapassam $80 \%$ das espécies.

Para descrever a estrutura da mata, os indivíduos foram separados em classes de diâmetro (Figura 4), e a forma do gráfico possui um aspecto distinto, chamado comumente de $\mathrm{J}$ invertido. Este aspecto mostra que a maioria dos indivíduos apresenta os menores diâmetros (diam. médio $=13,9 \mathrm{~cm}$ ); e que a circunferência das árvores é inversamente proporcional à sua abundância.

Dentre as espécies com indivíduos de mais de $50 \mathrm{~cm}$ de diâmetro estão: Hieronyma alchorneoides, Virola bicuhyba, Terminalia januariensis, Hymenea courbaril, Alchornea triplinervia, Sloanea guianensis e Sclerolobium denudatum.

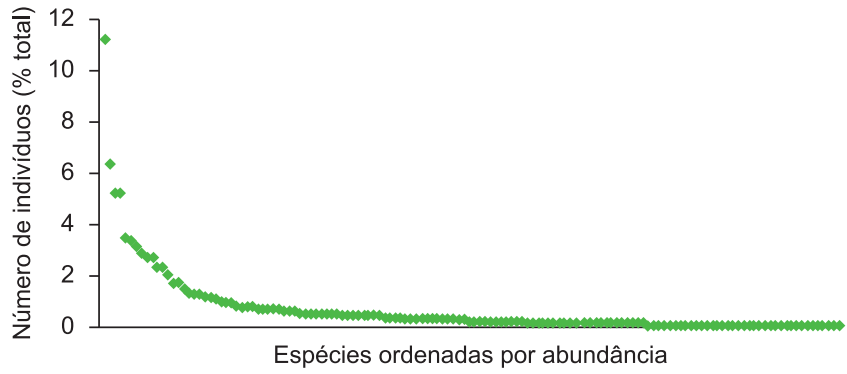

Figura 3. Diagrama de Whittaker, com as espécies alinhadas em ordem de abundância por abundância relativa.

Figure 3. Whittaker diagram with species aligned by relative abundance.
As espécies de menor diâmetro, que compõem o subdossel, são principalmente Euterpe edulis, Mollinedia schottiana, Guapira opposita e diversas da família Myrtaceae.

Similarmente, as alturas dos indivíduos foram separadas em classes de um metro (Figura 5). Apesar da moda estar entre 6 e $8 \mathrm{~m}$ e a média ser $9 \mathrm{~m}$ (desvio padrão 4,96 m), o dossel da mata fica a $18 \mathrm{~m}$. Os indivíduos de maiores alturas são das mesmas espécies com maior diâmetro, além de Syagrus pseudococos, que chega a grandes alturas mesmo sem ter crescimento secundário verdadeiro.

As oito espécies com maior IVI (Índice de Valor de Importância) somam pouco mais de um terço do IVI total, e são (em ordem de IVI): Euterpe edulis, Mollinedia schottiana, Bathysa mendoncaei, Coussarea accedens, Rustia formosa, Guapira opposita, indivíduos mortos e Chrysophyllum flexuosum. A lista completa de IVI, com as contribuições de freqüência relativa, dominância relativa e densidade relativa encontra-se no Anexo 2 (disponível na versão online, como Supplementary Online Material/SOM).

Quanto às famílias, Myrtaceae e Rubiaceae tiveram valores de IVI praticamente iguais (46,1 e 45,1, respectivamente); assim como seus IVCs (Índice de Valor de Cobertura); 33,3 para Myrtaceae e 33,5 para Rubiaceae. Seguem as famílias Arecaceae, Sapotaceae, Monimiaceae, Fabaceae e Nyctaginaceae, assim ordenadas tanto para o IVI quanto para o IVC (Anexo 3 disponível na versão online, como Supplementary Online Material/SOM).

A Tabela 3 apresenta uma lista dos indivíduos que nasceram sobre a rocha, mas lançaram raízes para o solo e daqueles que sobrevivem inteiramente sobre a rocha. A altura e diâmetro médios dos indivíduos que crescem sobre rochas não diferiu significativamente da altura e diâmetro de todos os indivíduos amostrados.

No entanto, a florística sobre rochas é diferente daquela da parcela como um todo, pois dentre as 29 espécies com 10 ou mais indivíduos, somente 13 ocorrem sobre rochas, e dentre elas, predominantemente Euterpe edulis (com 29\% de seus indivíduos sobre rochas), Guapira opposita (25\%) e Cecropia glaziovi (20\%).

Também foi feita uma análise da relação entre as rochas e os atributos da comunidade de cada subparcela. As subparcelas foram separadas nas cinco classes de rochosidade e foi calculado para cada uma destas classes o valor médio de riqueza, número de indivíduos, altura média e diâmetro médio. Foi possível observar que há tendência

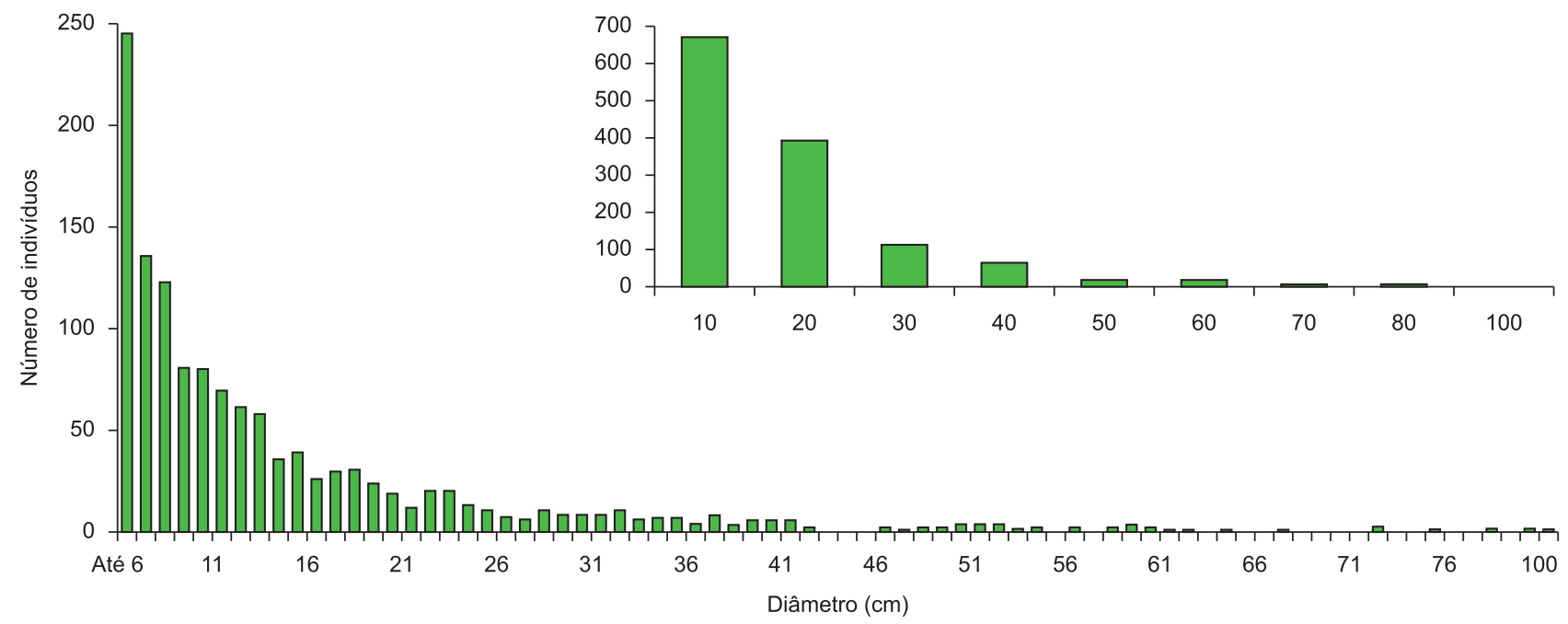

Figura 4. Classes de diâmetro de $1 \mathrm{em} 1 \mathrm{~cm}$ (janela maior) e a cada $10 \mathrm{~cm}$ (detalhe).

Figure 4. Classes of diameter by increments of $1 \mathrm{~cm}$ (larger graph) and by increments of $10 \mathrm{~cm}$ (detail). 


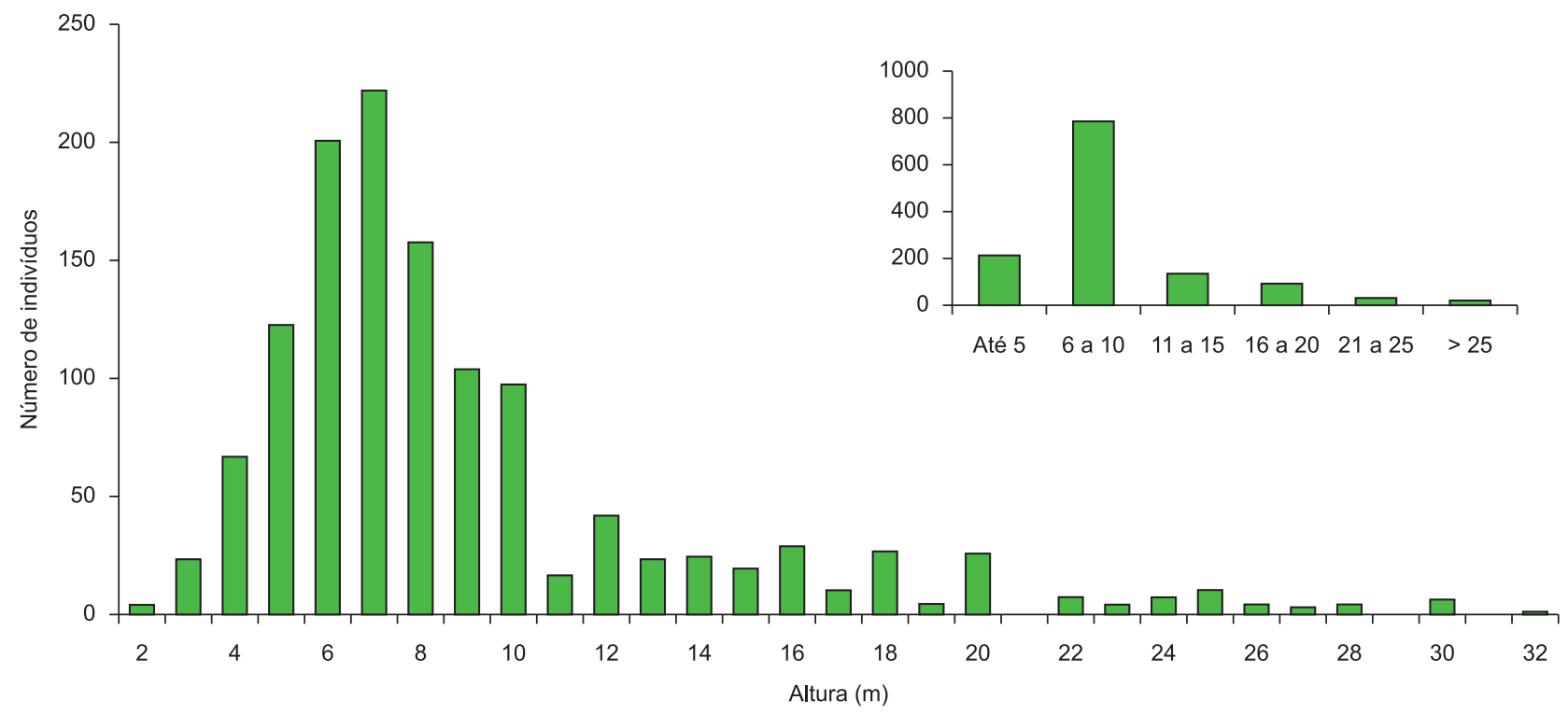

Figura 5. Contagem de indivíduos em cada classe de altura. No quadro maior, classes de 1 m. No quadro menor, classes de 5 m.

Figure 5. Counts of individuals in each height class. In the larger window, classes have an increment of $1 \mathrm{~m}$. In the smaller window, classes have an increment of $5 \mathrm{~m}$.

Tabela 3. Lista de espécies que crescem diretamente sobre rochas; com ou sem raízes lançadas no solo.

Table 3. List of species that grow directly on top of rocks; with or without roots sent around it down to the soil.

\begin{tabular}{|c|c|c|}
\hline \multirow[t]{2}{*}{ Espécie } & \multicolumn{2}{|c|}{ Raiz no solo } \\
\hline & Com & Sem \\
\hline Alchornea triplinervia & 1 & - \\
\hline Alseis floribunda & 2 & - \\
\hline Bathysa australis & 2 & - \\
\hline Bathysa mendoncaei & 4 & - \\
\hline Cecropia glaziovi & - & 2 \\
\hline Dendropanax cuneatus & - & 1 \\
\hline Eugenia cf. cereja & 1 & - \\
\hline Euterpe edulis & 8 & 33 \\
\hline Ficus glabra & - & 2 \\
\hline Ficus pulchella & 1 & - \\
\hline Guapira opposita & 10 & - \\
\hline Hieronyma alchorneoides & 1 & - \\
\hline Inga edulis & - & 1 \\
\hline Licaria armeniaca & 2 & - \\
\hline Marlierea glazioviana & 1 & - \\
\hline Marlierea tomentosa & 1 & - \\
\hline Miconia sp. & - & 1 \\
\hline Mollinedia schottiana & 7 & 1 \\
\hline Morta & 1 & 2 \\
\hline Myrcia spectabilis & 2 & - \\
\hline Ocotea dispersa & 1 & - \\
\hline Ocotea glaziovii & 1 & - \\
\hline Ocotea velloziana & 3 & - \\
\hline Pouteria venosa & 1 & - \\
\hline Rapanea gardneriana & - & 1 \\
\hline Rhodostemonodaphne macrocalyx & - & 1 \\
\hline Rudgea coronata subsp. leiocarpoides & 1 & - \\
\hline Rustia formosa & 2 & - \\
\hline Schefflera calva & 2 & - \\
\hline Sloanea guianensis & 1 & - \\
\hline Syagrus pseudococos & - & 1 \\
\hline Total sobre rochas & 56 & 46 \\
\hline
\end{tabular}


de diminuição tanto no número de indivíduos como de espécies com o aumento da quantidade de rochas; enquanto a flutuação nos valores de altura e diâmetro médios dos indivíduos e área basal não apresenta relação com a quantidade de rochas afloradas (Figura 6a,b).

\section{Discussão}

\section{Variáveis ambientais}

O desnível de 25 m encontrado dentro da parcela de $100 \times 100 \mathrm{~m}$, a variação na inclinação entre subparcelas e na superfície ocupada por rochas afloradas reflete a condição geológica sobre a qual a floresta está firmada. Os processos naturais no atual domínio da Serra do Mar, uma região submetida a altas pluviosidades médias anuais e episódios prolongados de chuvas, envolvem intensa participação de movimentações de massa, e os escorregamentos e deslocamentos de solos e rochas acontecem ao longo de superfícies planas e inclinadas (Almeida \& Carneiro 1998). Segundo Mantovani (1993), o predomínio de Litossolo, com afloramentos rochosos, pode ser indicativo de floresta recente, e sem sítios consolidados para espécies que exijam solo profundo.

Vê-se que além do solo raso, há ocorrência freqüente de afloramento de leitos de rio. Este é o caso das subparcelas 91 a 94, onde há o máximo de rochas afloradas, e é possível ouvir o barulho da água corrente sob elas. Nestas parcelas há muitos indivíduos crescendo sobre as rochas e formando, com suas raízes, uma tela que prende partículas que formarão, um dia, um solo verdadeiro.

\section{Florística}

Assinalar as famílias Myrtaceae e Rubiaceae como as mais ricas e abundantes da Floresta Ombrófila Densa Atlântica não faz nada além de corroborar estudos anteriores (Lacerda 2001, Peixoto et al. 2004, Oliveira et al. 2001, entre outros). Myrtaceae possui enorme especiação, com possivelmente mil espécies no Brasil (Landrum \& Kawasaki 1997), das quais o gênero mais numeroso é Eugenia. Esse foco de diversidade leva Mori et al. (1983) a crer que este seja o centro de distribuição da família, que ocorre nos continentes que formavam a antiga Gondwana e na região mediterrânea (Sytsma et al. 2004). Neste trabalho, a família representa 19\% das espécies amostradas, muito similar aos $20 \%$ encontrados por Lacerda (2001) para a mesma região, porém, de 2 a $1.000 \mathrm{~m}$ de altitude.

Já Rubiaceae apresentou também muitas espécies (14), mas seus 222 indivíduos não estão distribuídos eqüitativamente entre elas; e sim, concentrados em quatro espécies muito abundantes: Bathysa mendoncaei, Coussarea accedens, Rustia formosa e Coussarea meridionalis. $R$. formosa e B. mendoncaei aparecem como as espécies de Rubiaceae mais presentes no trabalho de Moreno et al. (2003) na região de Imbé, litoral norte do Rio de Janeiro.

Fabaceae segue em riqueza de espécies (11), mas com dominância de Swartzia simplex var. grandifolia (15 indivíduos) e de Sclerolobium denudatum (10 indivíduos), esta última não amostrada no trabalho de Lacerda (2001) na mesma região. Esta família aparece com alta porcentagem de espécies em outros estudos em Mata Atlântica do Estado de São Paulo (Lacerda 2001, Oliveira et al. 2001), mas se destaca no Rio de Janeiro (Peixoto et al. 2004) (revisão), onde chega a ter $20,5 \%$ das espécies amostradas.

Euphorbiaceae, assim como Fabaceae, apresenta dominância dividida entre duas espécies dentre o total de oito: Pausandra morisiana e Alchornea triplinervia. Também com oito espécies está Lauraceae, seguida de Moraceae e Sapotaceae, com sete espécies cada. Chrysophyllum flexuosum (Sapotaceae) é a sexta espécie em abundância de toda a parcela.

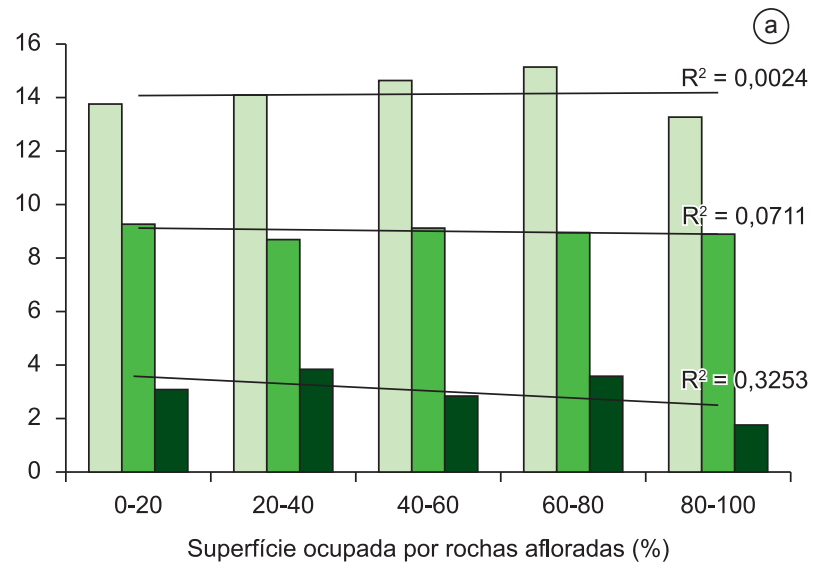

$\square$ Diam. médio $(\mathrm{cm}) \quad \square$ Alt. média $(\mathrm{m}) \quad \square$ Área basal $\left(\mathrm{cm}^{\wedge} 2 \times 0,1\right)$

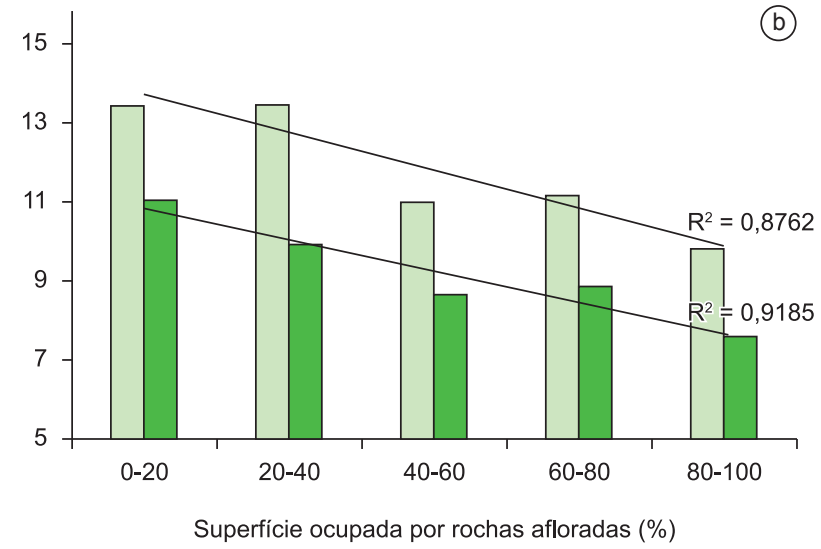

$\square$ Número de indivíduos $\quad \square$ Riqueza

Figura 6. a) Ausência de relação de rochas afloradas com diâmetro médio dos indivíduos, altura média e área basal; e b) relação inversamente proporcional entre quantidade de rochas afloradas e número de indivíduos e riqueza.

Figure 6. a) Absence of a relationship between rock outcrops and mean tree diameter, mean tree height and mean basal area; and b) Inverse relationship between the number of outcrop rocks and the number of trees and species richness.

Kurtz \& Araújo (2000) encontraram em um trabalho em Floresta Ombrófila Densa Submontana Sapotaceae como a família mais importante, e destacaram também, Rutaceae $\left(3^{\circ}\right)$ e Meliaceae $\left(4^{\circ}\right)$, que neste estudo ficaram respectivamente, na $42^{\mathrm{a}}$ e $25^{\mathrm{a}}$ posições de Valor de Importância. Isso demonstra que muitas vezes a composição de famílias e até mesmo espécies pode ser muito similar, mas as espécies dominantes em cada local são diferentes. Isso pode ser explicado pelas trajetórias distintas que cada trecho da floresta segue, de acordo com eventos estocásticos e a resposta dos indivíduos a eles.

As Melastomataceae, que aparecem em abundância em algumas regiões próximas, estão representadas nesta área de estudo por apenas um indivíduo de Miconia. O critério de inclusão (PAP $\geq 15 \mathrm{~cm}$ ) não favorece a amostragem da família, que geralmente possui troncos delgados, mas as observações de campo sugerem que mesmo nas classes menores de tamanho, são poucos indivíduos pertencentes a essa família.

A família Bignoniaceae, importante em Peruíbe devido à presença em abundância de Tabebuia obtusifolia (segunda espécie mais 
importante no estudo de Oliveira et al. (2001)) não foi amostrada nesta parcela. Similarmente, Aquifoliaceae, uma família comumente considerada importante em trabalhos na Mata Atlântica, e reportada em Ubatuba (Lacerda 2001) e em Iguape (Mantovani 1993, Carvalhaes 1997) não foi encontrada neste estudo. Esta variação regional, que contribui para a diversidade beta, provavelmente está mais associada a fatores edáficos e hídricos do que de dispersão da espécie, e é uma questão interessante para estudos posteriores.

Illenseer \& Paulilo (2002) estudaram características fisiológicas das plântulas de Euterpe edulis, para tentar compreender sua dominância em muitas áreas de Mata Atlântica. Em seu trabalho, notaram que a escassez de fósforo e nitrogênio não afetam o crescimento das plântulas, que também podem aproveitar a abertura de clareiras e o aumento de irradiância devido à sua plasticidade de aumentar a eficiência na absorção dos nutrientes e na assimilação de carbono líquido, dando a esta espécie maior competitividade. No presente estudo, também ficou estabelecido que a possibilidade de ocupação de rochas nuas é mais uma característica que favorece a ocorrência de E. edulis nas encostas da Floresta Ombrófila Densa Atlântica.

As seis espécies mais abundantes que seguem Euterpe edulis (com 40 indivíduos ou mais) são, como esta, características do subosque, e todas de caráter secundário tardio ou climácico (sensu Mantovani 1993). As três espécies pioneiras: Cecropia glaziovi, Aegiphila sellowiana e Tetrorchidium rubrivenium (sensu Mantovani 1993, Oliveira 1999) encontradas num total de 13 indivíduos corroboram a observação inicial de que a mata é pouco perturbada, mesmo com a proximidade da comunidade do sertão da Casa de Farinha e com o uso da trilha que cruza a parcela.

Muitas espécies amostradas foram classificadas por Mantovani (1993) como de distribuição exclusiva de Floresta Montana. A classificação deste autor reflete a escassez de dados para a Encosta Atlântica, possivelmente pela dificuldade de se trabalhar em terreno tão acidentado.

A classificação da fisionomia de Floresta Ombrófila Densa Submontana poderá ser posta em xeque assim que as demais parcelas do Projeto Temático Biota Gradiente estiverem completas. Por enquanto, é possível comparar este hectare com um de Floresta de Restinga (ou Terras Baixas), que tem 88 espécies dentro dos mesmos critérios de inclusão e apenas 29 espécies em comum (Carlos Joly, comunicação pessoal).

\section{Fitossociologia}

A alta diversidade encontrada para a parcela $\left(H^{\prime}=4,051\right.$ nats/ind $)$ reflete tanto o grande número de espécies encontrado (142), quanto a eqüabilidade $(J=0,817)$, sendo que a espécie dominante apresenta somente cerca de $11 \%$ dos indivíduos.

A alta riqueza e alta diversidade das florestas tropicais possuem muitas hipóteses explicativas. Pianka (1966) credita o aumento de diversidade nos trópicos às interações específicas dos predadores e maior intensidade de predação. Já Rohde (1992) acredita que a alta diversidade está ligada ao tempo de evolução nos trópicos, que é, por sua vez, determinado pelos tempos de geração, taxas de mutação e velocidade na seleção associados às altas temperaturas. Segundo Givnish (1999), a origem da alta diversidade em regiões tropicais pode estar relacionada à estabilidade climática, que permite baixas taxas de extinção, alta especiação e partição fina de nichos. A manutenção dessa diversidade reside na partição espaço-temporal das condições requeridas, no balanço não equilibrado de morte, competição e recrutamento, nas variações randômicas de abundância, na alta produtividade e na mortalidade densidade-dependente (Givnish 1999). De fato, essa última hipótese de manutenção de diversidade é corroborada por Wright (2002), quando o autor propõe que a redução no recrutamento perto da planta-mãe pode levar a um aumento da diversidade alfa, e quanto maior a diversidade alfa, menor deve ser a sobreposição no uso de recursos, e menor a competição entre os indivíduos. No entanto, o estudo de Lambers et al. (2002) descarta a mortalidade densidade-dependente como mecanismo de manutenção da alta diversidade nos trópicos, mas não propõe outro mecanismo.

Os dados de diversidade e eqüabilidade aqui apresentados são semelhantes aos citados na literatura (Martins 1993, Peixoto et al. 2004) para o sudeste brasileiro. É esperado encontrar uma diversidade ainda maior em áreas amostrais maiores, pois a inclusão de espécies raras somente aumenta o valor do Índice de Shannon, como pode ser visto ao se comparar este trabalho com o de Lacerda (2001), com os mesmos critérios de inclusão e também realizado à margem do Rio da Fazenda; que obteve $H^{\prime}=3,72$ para 0,18 ha e $H^{\prime}=3,86$ para 0,4 ha. Curiosamente, o valor de $\mathrm{J}$ decresce com o aumento do tamanho amostral $(0,88 ; 0,84$ e 0,82$)$.

O ajuste dos dados de abundância de espécies aos modelos logarítmicos é esperado quando se possui um número grande de espécies, pois elas se relacionam aos nichos de forma mais complexa do que comunidades com poucas espécies (Whittaker 1978).

A quantidade de espécies raras é alta, sendo que 39 espécies são representadas por um único indivíduo no hectare $(27,6 \%$ das espécies). Valores similares foram encontrados por Guilherme et al. em 2004 (23,8\%) e Oliveira et al. (2001) (31,7\%). Martins (1993) relaciona porcentagens de singletons, como são chamadas as espécies com somente um indivíduo para vários estudos da Mata Atlântica, e os valores variam de 9,2\% em Santa Catarina a 64,3\% em São Paulo. As metodologias e os critérios de inclusão alteram o resultado, em geral superestimando-o (Magurran 2005), mas os valores podem servir como parâmetro, ao menos.

Mas, ao mesmo tempo, é levantada a questão da raridade em si: é possível colocar um limite arbitrário entre espécies raras e abundantes? Seria a raridade uma característica da espécie; um efeito de amostragem; ou ainda, um limite de distribuição de uma espécie rica em um local mais afastado? Para Mantovani (1993), o conceito de espécies raras deve considerar diferentes escalas de análise, e para que se possa dirigir a esta questão, é necessário juntar dados de abundância e distribuição geográfica de cada espécie amostrada.

As árvores amostradas neste trabalho têm diâmetro médio de $13,9 \mathrm{~cm}$ e altura média de $9 \mathrm{~m}$. Os dados de outros autores no Sudeste mostram curvas com o mesmo padrão de distribuição e valores de 12,8 e 10,2 m (Guilherme et al. 2004), e 15,1 e 9,5 m (Oliveira 1999); ou seja, de diâmetro similar, mas altura média ligeiramente maior. É importante ressaltar que as alturas das árvores são, por regra, estimadas, e não medidas, e que, portanto, erros podem ocorrer.

Já quando comparada com a Floresta Amazônica, a Mata Atlântica pode ser considerada como uma floresta de baixo porte. Este fato é devido em grande parte à topografia regional. As árvores dos terrenos inclinados da encosta Atlântica recebem mais irradiação, e, ao mesmo tempo, estão mais sujeitas a danos provocados por ventos, chuvas e deslizamentos de terra. A combinação desses fatores com o clima leva ao estabelecimento do dossel mais baixo.

Assim sendo, com grandes diâmetros e alturas menores, a inclinação da linha de tendência para a relação alométrica das árvores é menor na Floresta Atlântica. Embora a comparação pareça trivial, os valores absolutos de altura dos indivíduos são muito importantes em estimativas de biomassa, por exemplo, que muitas vezes consideram apenas a área basal e poderiam superestimar os valores na Mata Atlântica (Vieira et al. 2008).

As rochas presentes na área amostral, que chegam a $5 \mathrm{~m}$ de diâmetro, ocupam espaço no solo que poderia ser ocupado por plantas. Isso explica a diminuição no número de indivíduos em áreas com 
maior superfície ocupada por afloramentos. O menor número de indivíduos acarreta em menor riqueza média de espécies.

Já a área basal das subparcelas mais rochosas não difere estatisticamente das de solo contínuo. Tampouco a altura média dos indivíduos e seu diâmetro médio são influenciados pelas rochas, contrariando a sugestão de Kurtz \& Araújo (2000), que afirmam que os afloramentos rochosos são um motivo que dificulta o desenvolvimento de árvores de maior porte. Nem mesmo a altura e diâmetro dos indivíduos que crescem sobre as rochas nuas é afetado, embora as espécies capazes de fazê-lo sejam poucas.

Euterpe edulis, que é a espécie que mais ocorre sobre rochas na área amostral, possui raízes que ficam expostas e funcionam como escora. A maioria delas $(80 \%)$ não lança raízes para o solo. Três indivíduos desta espécie, sobre rochas, foram encontrados caídos na última viagem de campo, depois da temporada de chuvas. Estes indivíduos certamente morrerão, pois estas palmeiras não possuem a capacidade de rebrotar. Mesmo assim, a ocorrência de E. edulis sobre rochas completamente nuas impressiona tanto pela estabilidade das árvores, como pela aparente eficiência no uso de água e nutrientes.

Outra espécie com ocorrência sobre rochas maior do que esperada é Guapira opposita, que aparentemente possui um mecanismo diferente para sobrevivência nesta condição. As plântulas são capazes de germinar sobre as rochas, mas todas as 10 árvores com $\mathrm{PAP} \geq 15 \mathrm{~cm}$ possuem uma grande raiz que chega ao solo, mesmo no caso de um indivíduo crescendo sobre uma rocha de $3 \mathrm{~m}$ de altura.

A ocorrência de afloramentos rochosos que ocupam parte da superfície é bastante freqüente na Floresta Ombrófila Densa do litoral Norte de São Paulo e no Rio de Janeiro, mas trabalhos com afloramentos rochosos normalmente tratam de outro tipo de afloramento: os inselbergs: enormes rochas nuas como o Pão de Açúcar (Meirelles et al. 1999).

\section{Agradecimentos}

Este trabalho foi financiado pela Fundação de Amparo à Pesquisa do Estado de São Paulo (FAPESP) no âmbito do Projeto Temático Gradiente Funcional: Composição florística, estrutura e funcionamento da Floresta Ombrófila Densa dos Núcleos Picinguaba e Santa Virgínia do Parque Estadual da Serra do Mar (Processo 03/12595-7), que faz parte do Programa BIOTA/FAPESP - O Instituto Virtual da Biodiversidade (www.biota.org.br). Autorização COTEC/IF 41.065/2005 e autorização IBAMA/CGEN 093/2005. Agradecemos também ao Programa de Pós-graduação em Biologia Vegetal da Universidade Estadual de Campinas, e à FAPESP pela bolsa de Mestrado da primeira autora. Finalmente, agradecemos aos colegas que colaboraram com o trabalho de campo, identificação do material e comentários no texto.

\section{Referências Bibliográficas}

ALMEIDA, F.F.M. \& CARNEIRO, C.D.R. 1998. Origem e evolução da Serra do Mar. Rev. Bras. Geocienc. 28(2):135-150.

ANGIOSPERM PHYLOGENY GROUP - APGII. 2003. An update of the Angiosperm Phylogeny Group classification for the orders and families of flowering plants: APG II. Bot. J. Linn. Soc. 141:399-436. http://dx.doi. org/10.1046/j.1095-8339.2003.t01-1-00158.x

CARVALHAES, M.A. 1997. Florística e estrutura de mata sobre restinga na Juréia, Iguape, SP. Dissertação de Mestrado, Universidade de São Paulo, São Paulo.

CLARK, D.B., CLARK, D.A. \& READ, J.M. 1998. Edaphic variation and the mesoscale distribution of tree species in a neotropical rain forest. J. Ecol. 86:101-112. http://dx.doi.org/10.1046/j.1365-2745.1998.00238.x

FIDALGO, O. \& BONONI, V.L.R. 1984. Técnicas de coleta, preservação e herborização de material botânico. Instituto de Botânica, São Paulo.
GIVNISH, T.J. 1999. On the causes of gradients in tropical tree diversity. J. Ecol. 87:193-210. http://dx.doi.org/10.1046/j.1365-2745.1999.00333.x

GUILHERME, F.A.G., MORELLATO, L.P.C. \& ASSIS, M.A. 2004. Horizontal and vertical tree community structure in a lowland Atlantic Rain Forest, Southeastern Brazil. Rev. Bras. Bot. 27(4):725-737.

INSTITUTO BRASILEIRO DE GEOGRAFIA E ESTATÍSTICA - IBGE. 2007. http://mapas.ibge.gov.br/ (ultimo acesso em: 26/11/2007).

ILLENSEER, R. \& PAULILO, M.T.S. 2002. Crescimento e eficiência na utilozação de nutrientes em plantas jovens de Euterpe edulis Mart. Sob dois níveis de irradiância, nitrogênio e fósforo. Acta Bot. Bras. 16(4):385-394. http://dx.doi.org/10.1590/S0102-33062002000400002

JOLY, C.A., ASSIS, M.A., BERNACCI, L.C., TAMASHIRO, J.Y., CAMPOS, M.C.R., GOMES, J.A.M.A., LACERDA, M.S., SANTOS, F.A.M., PEDRONI, F., PEREIRA, L.S., PADGURSCHI, M.C., PRATA, E.M.B., RAMOS, E., TORRES, R.B., ROCHELE, A., MARTINS, F.R; ALVES, L.F., VIEIRA, S.A., MARTINELLI, L.A., CAMARGO, P.B., SIMÕES, E., VILLANI, J.P. \& BELINELLO, R. 2011. Florística e fitossociologia da Mata Atlântica do sudeste do Brasil ao longo de um gradiente altitudinal. Biota Neotrop. 11(2):no prelo.

KURTZ, B.C. \& ARAÚJO, D.S.D. 2000. Composição florística e estrutura do componente arbóreo de um trecho de Mata Atlântica na Estação Ecológica Estadual do Paraíso, Cachoeiras de Macacu, Rio de Janeiro, Brasil. Rodriguésia 51(78-115):69-112.

LACERDA, M.S. 2001. Composição florística e estrutura da comunidade arbórea num gradiente altitudinal da Mata Atlântica. Tese de Doutorado, Universidade Estadual de Campinas, Campinas.

LAMBERS, J.H.R., CLARK, J.S. \& BECKAGE, B. 2002. Density-dependent mortality and the latitudinal gradient in species diversity. Nature 417:732-735. PMid:12066182. http://dx.doi.org/10.1038/nature00809

LANDRUM, L.R. \& KAWASAKI, M.L. 1997. The genera of Myrtaceae in Brazil: an illustrated synoptic treatment and identification keys. Brittonia 49(4):508-536. http://dx.doi.org/10.2307/2807742

MAGURRAN, A.E. 2005. Species abundance distributions: pattern or process? Funct. Ecol. 19:177-181. http://dx.doi.org/10.1111/j.02698463.2005.00930.x

MANTOVANI, W. 1993. Estrutura e dinâmica da Floresta Atlântica na Juréia, Iguape - SP. Tese de Livre Docência, Universidade de São Paulo, São Paulo.

MARTINS, F.R. 1993. Estrutura de uma floresta mesófila. Universidade de Campinas, Campinas. 246p.

MARTINS, S.C. 2010. Perdas de nitrogênio pela emissão de óxido nitroso $\left(\mathrm{N}_{2} \mathrm{O}\right)$ e sua relação com a decomposição da serapilheira e biomassa de raízes na floresta de Mata Atlântica. Tese de Doutoramento, Universidade de São Paulo, São Paulo.

MEIRELLES, S.T., PIVELLO, V.R. \& JOLY, C.A. 1999. The vegetation of granite rock outcrops in Rio de Janeiro, Brazil, and the need for its protection. Environ. Conserv. 26:10-20. http://dx.doi.org/10.1017/ S0376892999000041

MORENO, M.R., NASCIMENTO, M.T. \& KUTRZ, B.C. 2003. Structure and floristic composition of tree communities in two altitudinal zones in Atlantic Forest in the Imbé Region, RJ, Brazil. Acta Bot. Bras. 17(3):371-386.

MORI, S.A., BOOM, B.M., CARVALINO, A.M. \& SANTOS, T.S. 1983. Ecological importance of Myrtaceae in na Eastern Brazilian Wet Forest. Biotropica 15(1):68-70. http://dx.doi.org/10.2307/2388002

OLIVEIRA, R.J. 1999. Dinâmica de plântulas e estrutura de Mata Atlântica secundária de encosta, Peruíbe, SP. Dissertação de Mestrado, Universidade de São Paulo, São Paulo.

OLIVEIRA, R.J., MANTOVANI, W. \& MELO, M.M.R.F. 2001 Structure of the tree and shrub component of the Atlantic rain forest, Peruíbe, SP. Acta Bot. Bras. 15(3):391-412. http://dx.doi.org/10.1590/S010233062001000300009 
OLIVEIRA-FILHO, A.T. \& FONTES, M.A.L. 2000. Patterns of floristic differentiation among Atlantic Forests in Southeastern Brazil and the influence of Climate. Biotropica 32(4b):793-810. http://dx.doi. org/10.1111/j.1744-7429.2000.tb00619.x

PEIXOTO, G.L., MARTINS, S.V., SILVA, A.F. \& SILVA, E. 2004. Floristic survey of the tree layer in an area of Atlantic Rainforest in Serra da Capoeira Grande Environmental Protection Area, Rio de Janeiro State, Brazil. Acta Bot. Bras. 18(1):151-160.

PIANKA, E.R. 1966. Latitudinal gradients in species diversity: a review of concepts. Am. Nat. 100:33-46. http://dx.doi.org/10.1086/282398

REJMANÉK, M. 1977. The concept of structure in Phytosociology with references to classification of plant communities. Vegetatio 35(?):75-81.

ROHDE, K. 1992. Latitudinal gradients in species diversity: the search fot the primary cause. Oikos 65:514-527. http://dx.doi.org/10.2307/3545569

SÃO PAULO (Estado). 2007. Instituto Agronômico de Campinas. Centro Integrado de Informações Agrometereológicas. http://www.ciiagro. sp.gov.br/ (último acesso em: 04/05/ 2007).

SHEPHERD, G.J. 2006. FITOPAC I. Manual do Usuário. Universidade Estadual de Campinas, Campinas.
SYTSMA, K.J., LITT, A., ZJHRA, M.L., PIRES, J.C., NEPOKROEFF, M., CONTI, E., WALKER, J. \& WILSON, P.G. 2004. Clades, clocks, and continents: historical and biogeographical analysis of Myrtaceae, Vochysiaceae, and relatives in the Southern Hemisphere. Int. J. Plant Sci. 165(4Suppl.):S85-S105. http://dx.doi.org/10.1086/421066

VIEIRA, S.A., ALVES, L.F., AIDAR, M; ARAÚJO, L.S., BAKER, T., BATISTA, J.L.F., CAMPOS, M.C.R., CAMARGO, P.B., CHAVE, J., DELITTI, W.B., HIGUCHI, N., HONORIO, E., JOLY, C.A., KELLER, M., MARTINELLI, L.A., MATTOS, E.A., METZKER, T., PHILLIPS, O., SANTOS, F.A.M., SHIMABUKURO, M.T., SILVEIRA, M. \& TRUMBORE, S.E. 2008. Estimation of carbon stocks: the case of the Atlantic Forest. Biota Neotrop. 8(2): http://www.biotaneotropica.org.br/ v8n2/en/abstract?point-of-view+bn00108022008

WHITTAKER, R.H. 1978. The population structure of vegetation. In Phytosociology - Benchmark papers in ecology, vol. 6 (R.P McIntosh, ed.). Dowden, Hutchinson \& Ross, Inc, Pennsylvania, p.360-380.

WRIGHT, J.S. 2002. Plant diversity in tropical forests: a review of mechanisms of species coexistence. Oecologia 130(1):1-14.

Recebido em 31/03/2010

Versão reformulada recebida em 18/03/2011

Publicado em 20/05/2011 